www.periodicos.unimontes.br/index.php/caminhosdahistoria

\title{
O PERFIL SOCIAL DE MULHERES ELEITAS EM RORAIMA (2014-2016)
}

\author{
Yôkissya Coelho ${ }^{1}$ \\ Monalisa Pavonne Oliveira ${ }^{2}$
}

Recebido em: 18/04/2020

Aprovado em: 13/06/2020

Resumo: Este artigo pretende apresentar o perfil social das mulheres eleitas em Roraima a partir do pleito de 2014, utilizando como base o advento da Lei ${ }^{\circ} 12.034 / 2009$ que estabelece as regras para as eleições brasileiras. Para tanto utilizamos quatro mulheres eleitas. A exgovernadora Suely Campos do Partido Progressista (PP); a prefeita da capital Boa Vista, Teresa Surita do Partido Movimento Democrático Brasileiro (PMDB); a deputada federal Shéridan Estérfany Oliveira de Anchieta do Partido Social Democracia Brasileira (PSDB); e a ex-senadora Angela Maria Gomes Portela do Partido Democrático Trabalhista (PDT). Mergulhamos no universo biográfico de cada uma delas através da prosopografia, e com isso foi possível constatar a estratégia de ascensão social apoiada na dinâmica das redes sociais e verificar a continuidade de certos grupos políticos em Roraima. Desse modo, compreendemos que a presença direta das relações de parentesco se tornou um instrumento eficaz para a manutenção do poder político. Percebemos que através das redes de poder e proteção, políticos conseguem se manter em posições de mando.

Palavras-chave: Mulheres. Eleições. Política. Prosopografia. Roraima.

\section{EL PERFIL SOCIAL DE LAS MUJERES ELEGIDAS EN RORAIMA (2014-2016)}

Resumen: Este artículo tiene como objetivo presentar el perfil social de las mujeres elegidas en Roraima a partir de las elecciones de 2014, basado en el advenimiento de la Ley $\mathrm{N}^{\circ}$ 12.034 / 2009, que establece las reglas para las elecciones brasileñas. Para esto, utilizamos cuatro mujeres elegidas. La ex-gobernadora Suely Campos del Partido Progresista (PP); la alcaldesa de la capital, Boa Vista, Teresa Surita, del Partido del Movimiento Democrático Brasileño (PMDB); la diputado federal Shéridan Estérfany Oliveira de Anchieta del Partido Social demócrata Brasileño (PSDB); y la ex-senadora Angela Maria Gomes Portela del Partido Laborista Democrático (PDT). Nos sumergimos en el universo biográfico de cada una de ellas a través de la prosopografía, y con eso fue posible ver la estrategia de ascensión social respaldada por la dinámica de las redes sociales y verifique la continuidad de ciertos grupos políticos en Roraima. De esta manera, entendemos que la presencia directa de las relaciones de parentesco se ha convertido en un instrumento eficaz para mantener el poder político. Nos

\footnotetext{
${ }^{1}$ Mestranda do Programa de Pós-Graduação em Sociedade e Fronteiras - Universidade Federal de Roraima (UFRR), Brasil. Licenciada em História pela Universidade Federal de Roraima (UFRR). Email: coelhoyokissya@gmail.com. Orcid: https://orcid.org/0000-0002-2235-2993.

${ }^{2}$ Doutora em História pela Universidade Federal de Juiz de Fora (UFJF), Professora do curso de Licenciatura em História da Universidade Federal de Roraima (UFRR), Professora do Mestrado Profissional em História (ProfHistória) UFRR, Coordenadora do Grupo de Pesquisa História Colonial e Ensino de História (DPG/CNPq). E-mail: monalisapavonne@gmail.com. Orcid: https://orcid.org/0000-0002-0091-6778.
} 
dimos cuenta de que a través de las redes de poder y protección, los políticos logran permanecer en puestos de mando.

Palabras clave: Mujeres. Elecciones. Política. Prosopografia. Roraima.

THE SOCIAL PROFILE OF ELECTED WOMEN IN RORAIMA (2014-2016)

Abstract: This article intends to present the social profile of women elected in Roraima since the 2014 election, based on the advent of Law 12.034 / 2009, which establishes the rules for the Brazilian elections. For that we used four elected women. Ex-Governor Suely Campos from the Progressive Party (PP); the mayor of the capital Boa Vista, Teresa Surita from the Brazilian Democratic Movement Party (PMDB); federal deputy Shéridan Estérfany Oliveira de Anchieta from the Brazilian Social Democratic Party (PSDB); and ExSenator Angela Maria Gomes Portela from the Democratic Labor Party (PDT). We immersed ourselves in the biographical universe of each of them through prosopography, and with this we could verify the social ascension strategy based on the dynamics of social networks and check the continuity of certain political groups in Roraima. In this way, we understand that the direct presence of kinship relations has become an effective instrument for the maintenance of political power. We realize that through the networks of power and protection, politicians are able to remain in positions of command.

Keywords: Women. Elections. Policy. Prosopography. Roraima.

\section{Introdução}

Ao perceber a franca expansão de mulheres na política nacional, surgiu o interesse de analisar o perfil social das mulheres eleitas em Roraima, caminho ainda pouco explorado pela historiografia local. Inicialmente, usamos como base o marco da Lei $n^{\circ}$ 12.034/09 que estabeleceu as normas para as eleições brasileiras, de modo que a análise da lei ajudou a compreender a entrada dessas mulheres para os partidos políticos. Após a análise a respeito das eleições brasileiras ocorridas na região Norte durante os anos de 2002, 2006, 2010 e 2014, notamos um pequeno acréscimo no número de inclusão das mulheres na política. Em 2006 o número de candidatas eleitas para cargos nas esferas do executivo, legislativo e municipal era apenas de 32, já nas eleições de 2010 esse quantitativo subiu para 36, mostrando que após a minirreforma a participação feminina na política brasileira ainda continua pequena.

No entanto, o estado de Roraima é uma região que possui um número significativo de candidatas eleitas para cargos legislativos federais, estaduais e municipais, e por contar com uma a frente de um dos cargos executivos mais importantes do estado, a prefeita da capital Boa Vista, Teresa Surita do Partido do Movimento Democrático Brasileiro. Tendo em vista, a promulgação da Lei ${ }^{\circ}$ 12.034/2009 que estabelece as normas para as eleições brasileiras, no que corresponde ao número de vagas dos partidos reservadas às mulheres, ato chamado de "política de cotas" dos partidos políticos, cujo objetivo é garantir o acesso à candidatura feminina, e com isso inserir o princípio de equidade entre os sexos na política. Sendo assim, 
traçamos o perfil social de mulheres eleitas nos pleitos entre 2014 e 2016 para cargos executivos a nível estadual e municipal: governadora e prefeita, e legislativos em âmbito federal, no estado de Roraima, sendo eles: senadora e deputada federal.

Nessa direção, fez-se necessário analisar processo histórico de inserção das mulheres nos espaços de poder e também as dinâmicas das elites em Roraima. O objetivo geral do trabalho foi traçar o perfil social de quatro mulheres: a ex-governadora Suely Campos (PP); A prefeita Maria Teresa Saenz Surita (PMDB); A deputada federal Shéridan Estérfany Oliveira de Anchieta (PSDB); e a ex-senadora Angela Maria Gomes Portela (PDT). De onde vieram, família, formação acadêmica, cargos políticos etc. E como objetivos específicos, averiguamos como ocorreu a entrada dessas mulheres para os partidos políticos e identificamos as estruturas de parentesco que marcaram sua história. Nesse sentido, visamos saber se houve continuidade de certos grupos políticos, através da trajetória dessas mulheres.

Para tanto, realizamos uma discussão teórico-metodológica, iniciando pela História do Tempo Presente, campo da História que permite examinar os desdobramentos recentes. Somado à discussão teórica, lançamos mão do método prosopográfico, metodologia que tem como finalidade analisar o perfil de um grupo, grosso modo, traçar uma biografia coletiva a partir dos mais variados aspectos da vida dos membros de um determinado grupo, como: formação acadêmica, atuação profissional, filiação político-partidária, estado-civil, condição socioeconômica etc.

Nesse sentido, o presente artigo está dividido em três tópicos. No primeiro tópico, faremos uma discussão sobre História do Tempo Presente, a construção da elite política do Brasil, que tem sido foco de vários estudos, sobretudo no que concerne às relações de parentesco. Tendo em vista que para abordar mulheres na política, é necessário falarmos um pouco da elite política brasileira. Nesta seção, trataremos também da metodologia empregada no trabalho, a prosopografia, ferramenta utilizada para traçar os perfis de grupos políticos, com intuito de esclarecer aspecto que esses grupos possuem em comum.

No segundo tópico, discutiremos a criação do estado de Roraima, desde os primeiros governadores do antigo território até sua elevação a estado de Roraima. Quando novos agentes políticos são incorporados ao cenário político roraimense. No terceiro e último tópico, identificaremos o perfil social das mulheres eleitas em Roraima para os cargos executivos e legislativos, nas eleições de 2014 e 2016. Também revelaremos o que os dados obtidos através da prosopografia têm a dizer sobre essas mulheres. Para estudar o perfil dessas quatro mulheres, optamos por utilizar um questionário biográfico, no qual procuramos traçar os seguintes requisitos: local de origem, casamento, atividade profissional, situação e carreira 
política. E assim, comparar as informações obtidas, cujo objetivo é extrair as características sociopolíticas do conjunto de indivíduos estudados.

\section{História do Tempo Presente, elite brasileira e prosopografia}

A História do Tempo Presente, de acordo com Henry Rousso, é uma história:

Na qual o historiador investiga um tempo que é o seu próprio tempo com testemunhas vivas e com uma memória que pode ser a sua. A partir de uma compreensão sobre uma época que não é simplesmente a compreensão de um passado distante, mas uma compreensão que vem de uma experiência da qual ele participa como todos os outros indivíduos (ROUSSO, 2009, p. 202).

O conceito está ligado à criação entre os anos de 1978 e 1980 do Instituto de História do Tempo Presente (IHTP) na França, cuja função era investigar o passado próximo e a História Contemporânea. A História do Tempo Presente permite perceber como algumas questões podem encontrar eco na atualidade e assim servir de instrumental capaz de auxiliar nas análises de rupturas e permanências que marcam a sociedade hodierna. Neste sentido, e tendo como referência também o debate em Tânia Swain (2009), que pretendemos analisar a presença e atuação das mulheres nas esferas políticas de Roraima.

Em 2009, a Lei no 9.504 de 30 de setembro de 1997 que estabeleceu as normas para as eleições brasileiras sofreu alterações no que corresponde ao número de vagas dos partidos políticos. O texto de 1997 em seu Art. 10 estabelecia no " $§ 3^{\circ}$ Do número de vagas resultante das regras previstas neste artigo, cada partido ou coligação deverá reservar o mínimo de trinta por cento e o máximo de setenta por cento para candidaturas de cada sexo" (grifo nosso), entretanto a Lei $n^{\circ} 12.034$ de 29 de setembro de 2009 alterou a redação para " $\$ 3^{\text {o }}$ Do número de vagas resultante das regras previstas neste artigo, cada partido ou coligação preencherá o mínimo de 30\% (trinta por cento) e o máximo de $70 \%$ (setenta por cento) para candidaturas de cada sexo.” (grifo nosso) (PLANALTO, 2009). Portanto, entende-se que as mudanças nessas três palavras representaram o princípio de equidade política, isso porque os partidos políticos foram obrigados a introduzir as mulheres nesses espaços tradicionalmente ocupados por homens, o que representou uma medida de ação positiva destinada a promover a igualdade entre os sexos.

Desse modo, consideramos que o trabalho ora desenvolvido faz parte da história do Tempo Presente. Em linhas gerais, História do Tempo Presente quer dizer o estudo de como o presente é construído no tempo. Este novo campo da história desenvolveu-se principalmente na Alemanha e na França, após as duas grandes guerras mundiais, cujo objetivo era a 
documentação e a pesquisa desses temas. Portanto, a História do Tempo Presente será um dos fatores que romperá com o fazer historiográfico tradicional, que defendia a necessidade de distanciamento para a realização da análise histórica. (FERREIRA, 2000).

Segundo Ferreira (2000), a historiografia da Antiguidade Clássica encontrou nos testemunhos diretos uma forma de construir sua história. A utilização dos testemunhos sofreu desqualificação na segunda metade do século XIX, entretanto, foi restaurada no século XX por historiadores que defendiam a validade do estudo do tempo presente (p. 314, 2002). A demanda pelo estudo da história recente levou a comunidade dos historiadores a rever suas posições, ao permitir repensar as relações entre passado e presente. Existe um alerta para os perigos e desafios de se estudar o presente. Rousso afirma que o primeiro risco sempre foi a proximidade com objeto, pois o historiador precisa conseguir produzir a história do próprio tempo "tentando obter uma reflexão que permita um recuo relativo", pois conforme suas experiências vividas "fazer história do Tempo Presente é manter-se à distância face ao próprio presente, uma tarefa difícil” (2009, p. 209).

Toda essa complexidade criada em torno da História do Tempo Presente, gerou a necessidade de uma "prática consciente" de si própria, pois essa consciência impedirá qualquer ingenuidade frente ao fazer historiográfico, devido ao fato de que os historiadores do tempo presente são mais confrontados do que os outros.

$\mathrm{Na}$ tentativa de traçar o perfil social das mulheres eleitas em Roraima, utilizamos como metodologia a prosopografia, na definição de Lawrence Stone a prosopografia é:

A investigação das características comuns de um grupo de atores na história por meio de um estudo coletivo de suas vidas. O método empregado constitui em estabelecer um universo a ser estudado e então investigar um conjunto de questões uniformes - a respeito de nascimento e morte, casamento e família, origens sociais e posição econômica herdada, lugar de residência, educação, tamanho e origem da riqueza pessoal, ocupação, religião, experiência em cargos e assim por diante. Os vários tipos de informações sobre os indivíduos desse universo são então justapostos, combinados e examinados em busca de variáveis significativas. Eles são testados com o objetivo de encontrar tanto correlações internas quanto correlações com outras formas de comportamento ou ação (STONE, 2011, p. 115).

Por sua vez, Flávio Heinz também afirma que a prosopografia busca revelar características comuns, permanentes ou transitórias de um determinado grupo social, em certo momento histórico, através de uma abordagem sociológica (HEINZ, 2006, p.9). As definições desse método são múltiplas, mas como vimos nos dois conceitos, possui um elemento comum: a análise do indivíduo em função da totalidade do qual ele faz parte. 
A partir do método prosopográfico definimos o grupo a ser estudado, as mulheres eleitas em Roraima, formulamos um conjunto de questões sobre o nascimento, casamento, educação, família, cuja finalidade é analisar as características comuns desse grupo, que fazem parte de um grupo de atores da história política de Roraima. Nesse sentido, há também o interesse em mostrar as potencialidades dos arranjos familiares e dos vínculos de parentescos dessas mulheres, como ligações políticas, já que a pesquisa prosopográfica pode ser dedicada essencialmente a analisar esses elos familiares. Entretanto, a prosopografia não é apenas uma análise descritiva de um determinado grupo, é também a comparação das propriedades e atributos de coletividades no tempo e suas modificações estruturais (CODATO, HEINZ, 2015, p. 250).

A pesquisa prosopográfica mostra-se imprescindível para o trabalho, pois a estratégia da pesquisa foi definir um questionário biográfico, cujos diferentes critérios e variáveis vão servir para nos mostrar a dinâmica social, privada, pública e cultural das mulheres eleitas em Roraima. A prosopografia permite mergulhar no universo das elites, "estudos sobre perfis de elite permitem estimar movimentos de separação (ou não) de diferentes esferas das práticas sociais, em especial do universo político em relação ao mundo social" (CODATO, HEINZ, 2015, p. 249). Isto é, a prosopografia que introduziu novamente à pesquisa o estudo sobre a política, ajudando a superar uma carga negativa que antes era atribuída ao retorno da história política e das elites políticas. Essa volta tornou-se possível através da evolução e acessibilidade das técnicas de processamento de dados. E contribuíram para o desenvolvimento dos trabalhos da prosopografia contemporânea. (ALBERNAZ, 2011, p.13). Portanto, podemos concluir que a prosopografia não só nos ajudou na coleta de dados simples como a origem, casamento, filiação partidária e outros. Todavia, também, permitiu obter informações que explicam os padrões de comportamento político, de reprodução e renovação da elite política feminina roraimense.

A história das elites políticas encontrou uma segunda chance com a impulsão da prosopografia. Ocasionando a renovação dos seus métodos e problemáticas, como o estudo do comportamento da elite política e as características da sua origem. No Brasil a elite política nacional era composta principalmente por homens e de idade mais avançada, seus membros eram os proprietários de terras ou homens de negócios de algum tipo. Os títulos universitários eram muito importantes para a entrada na política brasileira, a educação universitária era virtual requisito para um alto posto político "a literatura mostra que as elites políticas tendem igualmente a serem formadas por profissionais de origem relativamente privilegiada, ligado a proprietários através de laços econômicos e sociais.” (BARICKMAN, LOVE, 2006, p.79). A 
participação em associações e sociedades profissionais foi essencial à elite política. (CORINIFF, 2006, p. 103). O grau de sucesso de uma elite é indicado pelo número de posições ocupadas.

No entanto, Coriniff nos atenta para um aspecto importante da elite política:

Nos primórdios do século XX, a elite política coincidia bastante com as elites sociais, econômicas e intelectuais. Cada vez mais, porém, disponibilizou-se o acesso ao cargo público a indivíduos de classe média, de modo que a política não mais se sobrepunha tanto às outras. Carreiras políticas tornaram-se meios de mobilidade ascendente para pessoas talentosas, com as qualificações certas. Essa tendência trouxe certo grau de democratização à sociedade brasileira, porque a liderança não mais estava restrita a um pequeno número de pessoas (CORINIFF, 2006, p. 100).

Mas, a medida que o século avançava, as configurações da elite política brasileira sofriam alterações. A entrada para a elite política era exercida por muitos meios, sendo o apadrinhamento uma prática marcante da política nacional. Havia também alguns sistemas de recrutamento da elite como a "política de governadores"3 e a "política dos coronéis"4. Esses sistemas favoreciam o presidente que podia de longe ter o controle e implantar suas medidas nos estados brasileiros com a ajuda dos governadores, e em troca governadores e coronéis detinham o total poder sobre as regiões. As mudanças que o Brasil passou após a presidência de Getúlio Vargas e a promulgação de uma nova Constituição do Estado Novo em 1937 tiraram da política de apadrinhamento a sua força. Sendo assim, Getúlio Vargas revisou o sistema político brasileiro ao extinguir a política dos governadores, queimando publicamente as bandeiras estaduais, ato que simbolizou a primazia do governo federal sobre os direitos dos estados (CORINIFF, 2006, p. 108).

No entanto, a política não era um fórum aberto para o choque de interesses em competição, no qual líderes ponderavam os lados e tomavam decisões baseadas nos méritos de cada caso. Em vez disso, a Constituição de 1937 centralizava e ampliava o poder do Presidente da República, que governava por meio de decretos-leis, também anulava o poder Legislativo e nomeava interventores para os cargos executivos nos governos dos estados e nas prefeituras municipais. Desse modo, eram os contatos pessoais, amizades, compromissos e laços de familiares que determinavam a posição de um líder. (CORINIFF, 2006, p. 113). Após a derrubada de Getúlio Vargas em 1945, a vida política no Brasil floresceu, fazendo

\footnotetext{
${ }^{3}$ A Política dos Governadores foi implantada durante o mandato do Presidente Campo Salles (1898-1902), cujo objetivo era controle dos estados brasileiros, esse domínio era feito através de alianças entre o presidente e governadores, que em troca recebiam total autonomia para comandar seus respectivos estados.

${ }^{4}$ Política dos coronéis ou coronelismo era uma aliança estabelecida entre governadores e chefes regionais, os coronéis tinham total poder sobre determinadas regiões, realizam eleições fraudulentas para candidatos dos governos.
} 
com que as eleições se tornassem o principal meio de entrada para a elite política. Entretanto, conforme as mudanças políticas do país, durante o golpe civil-militar, a elite política continuou existindo, no entanto ela mudou de composição, não mais controlava o acesso, as relações e o grau de poder exercido, tendo em vista que nesse momento, o poder estava nas mãos dos militares. Observando os desdobramentos da elite política brasileira, encontramos em Coriniff uma boa explicação:

Podemos generalizar que a elite política foi bastante exitosa em se manter no poder. Durante a República Velha, os chefes nos principais estados e no Rio de Janeiro administravam o sistema com raros desafios e recursos a força. Vargas revisou o sistema e reconstituiu a elite política, baseando-se em alguns elementos existentes, mas introduzindo também muitos atores novos. Durante duas décadas do experimento democrático, a elite política controlou os negócios públicos quase sem interrupção. O golpe de 1964 sacudiu o controle da elite quase tanto quanto a revolução de Vargas, mas, por fim uma elite reconsolidada recuperou a hegemonia (CORINIFF, 2006, p. 116).

São essas transformações dos perfis sociais e profissionais da elite brasileira que determinam a configuração de uma sociedade. Sendo assim, através da prosopografia o presente trabalho traçou alguns aspectos e conexões entre os indivíduos da elite política roraimense, que serão abordados mais adiante.

\section{A criação do estado de Roraima}

A fundação da cidade de Boa Vista se iniciou em 1858, quando a região recebe a denominação de Freguesia de Nossa Senhora do Carmo, antes fazenda de pecuária pertencente ao capitão Inácio Lopes de Magalhães, ficando assim definida como sua sede a localidade de Boa Vista. A pequena sociedade sofrerá mudanças com a criação do Território Federal em 1943, não havendo na região outra cidade com condições melhores, Boa Vista se tornou sua capital, evento que abriu as portas para uma nova fase da sua história. A presidência de Getúlio Vargas deu a ocupação da Amazônia um novo significado para o Estado Nacional (SANTOS, 2015, p. 63).

Passando para as décadas de 1970 e 1980, Santos afirma que esses períodos foram significativos para o processo histórico de Roraima como para sua historiografia, explica:

Sua população presenciava acontecimentos importantes: a abertura da BR174, que liga por terra Boa Vista a Manaus; a descoberta de grandes garimpos de ouro, o que acarretou um intenso processo migratório para a região; a consolidação do movimento indígena no Estado; a mudança de território Federal de Roraima para Estado de Roraima, com a Constituição de 1988 (SANTOS, 2015, p. 29). 
Nessa citação observa-se, que Boa Vista transformou-se em uma nova cidade. O garimpo se tornou uma importante atividade, tinha relação direta com os interesses das elites locais, e acabou atraindo diversos migrantes para Boa Vista.

No ano de 1979 assumiu o governo de Roraima o brigadeiro da Aeronáutica Ottomar de Souza Pinto (1979-1983), casado com Marluce Pinto, foi iniciador de uma nova política roraimense, ao nomear pessoas do próprio município, formando um secretariado tendo por base as forças locais. Ottomar se tornou uma figura muito popular e uma das fortes lideranças políticas em Roraima. A base política de Ottomar, que contava com o apoio de migrantes, era também ancorada em nepotismo, como no caso de sua esposa Marluce Pinto que coordenou a parte administrativa do setor social do seu governo.

A Constituição de 1988 trouxe mudanças para a região, transformou o Território Federal em estado de Roraima, inaugurando um novo momento para a região. Um exemplo disso está na primeira eleição para governador, ocorrida em 1990, quando ficaram frente a frente na disputa Romero Jucá Filho e o brigadeiro Ottomar de Souza Pinto, vencendo este último apoiado pelas forças nativistas. Romero Jucá iniciou sua carreira política em Pernambuco (PE), transferiu-se para Roraima ano de 1988 junto da sua ex-esposa Maria Teresa Saenz Surita, como último governador do então Território Federal, tornando-se meses depois o primeiro governador do recém-criado estado de Roraima. Analisar a trajetória de Romero Jucá e dos quatro últimos governadores de Roraima é importante para compreender como se deu construção dos grupos políticos roraimenses. Esses governos e alianças servirão de estrutura para que as mulheres analisadas na pesquisa entrem para a política, como mostra o terceiro tópico.

A partir da instalação do estado em 1990, os grupos políticos vão se estruturando em torno de Ottomar, de Jucá e de outros personagens de menor peso político. É quando na segunda metade dos anos 1990, estrutura-se outro grupo, em torno de Neudo Campos, empresário local da construção civil. Nasceu na cidade de Boa Vista (RR) em 1946, casado com a ex-governadora de Roraima, Suely Campos, é formado em engenharia, e sua carreira política é marcada por diversos escândalos de corrupção. Envolvido em um processo criminal pelo caso conhecido como "Gafanhotos", Neudo Campos renunciou ao cargo de governador, seu vice Francisco Flamarion Portela assumiu seu lugar, nascido em Coreaú (CE). Flamarion Portela é casado com Angela Maria Portela (PDT), ex-senadora de Roraima. Os dois

\footnotetext{
5 A operação conhecida como Gafanhotos, foi uma operação policial desenvolvida pela Polícia Federal de Roraima, com a finalidade de desarticular e colher provas sobre o desvio de dinheiro público por parlamentares, ex-parlamentares e altos funcionários do Executivo Federal (Fonte: Folha de Boa Vista).
} 
migraram juntos para o Território de Roraima em 1985. Elegeu-se vice-governador de Roraima em 1998, na chapa liderada por Neudo Campos (PPB).

Em janeiro de 2003, Flamarion Portela tomou posse no governo do estado de Roraima, quando surgiram denúncias de que teria utilizado a máquina pública para garantir sua eleição para o governo do estado. Em agosto de 2004, Flamarion Portela teve seu mandato cassado pelo Tribunal Superior Eleitoral (TSE), novamente em virtude de um processo em que foi acusado de abuso de poder político e econômico na campanha de sua reeleição, quando teria utilizado programas sociais do estado para se promover. O processo foi movido por seu adversário nas eleições, Ottomar Pinto, então do PTB, que venceu o primeiro turno, mas perdeu o segundo, por uma pequena margem de votos, com a cassação de Portela, foi conduzido ao governo estadual pela Justiça Eleitoral, em novembro de 2004 (Dicionário Histórico Biográfico Brasileiro, 2009).

Ao se tornar governador novamente, Ottomar introduziu no cenário político roraimense um novo nome, José de Anchieta Júnior, de Jaguaribe (CE). Anchieta mudou-se para Boa Vista no ano de 1991, e se estabeleceu no ramo da construção civil. Em 2004, assumiu o seu primeiro cargo público como Secretário de Estado da Infraestrutura, no governo Ottomar Pinto, assumindo temporariamente no mesmo ano a Secretaria de Estado da Articulação Municipal. Em 2006, foi eleito vice-governador pelo PSDB na chapa de Ottomar Pinto, para o mandato de 2007 a 2010. Anchieta também foi casado com a atual deputada federal Sherydan Anchieta (PSDB). Com a morte de Ottomar Pinto, Anchieta assumiu o governo do estado em 11 de dezembro de 2007. Reeleito em 2010, renunciou ao cargo de governador em quatro de abril de 2014 para ser candidato ao senado, não conseguindo se eleger (Dicionário Histórico Biográfico Brasileiro, 2013). Anchieta durante as eleições de 2019, quando se candidatou ao governo do estado, sofreu um infarto e veio a falecer.

De acordo com o panorama exposto, de alguns governadores do estado, passemos então à análise de nosso objeto de pesquisa.

\section{Perfil social das mulheres eleitas para os cargos executivos e legislativos nas eleições de 2014 e 2016}

Para abordar a atuação das mulheres na política de Roraima, toma-se como ponto de partida o ingresso no debate sobre o conceito de gênero. A palavra gênero tem caráter polissêmico, ou seja, mais de um significado, dependendo de uma determinada corrente teórica, a interpretação do que é masculinidade e feminilidade pode ser entendida de formas 
diferentes. Entretanto, o modelo mais usado nas sociedades contemporâneas está vinculado a uma estrutura corpórea, quando, ao falar de feminilidade e masculinidade faz-se referência ao corpo do homem e da mulher. Todavia não o corpo como um todo, mas a genitália.

Desse modo, o mundo vive numa espécie de divisão, que chamamos de binária, que reparte as pessoas entre homens e mulheres, é essa separação que determina para esses indivíduos os papéis sociais a serem seguidos. Consequentemente, o gênero, como afirma Joan Scott, se torna uma forma de indicar as "construções sociais", a criação inteiramente social das ideias sobre os papéis próprios aos homens e às mulheres, passando a ser uma categoria social imposta sobre um corpo sexuado. (SCOTT, 1989, p. 3). A divisão binária sustentará as diversas crenças e condutas que dão sentido ao que é ser homem e mulher. Embasando a compreensão de que a partir da diferença biológica entre os sexos, surgiram as justificativas naturais das diferenças socialmente construídas entre os gêneros, principalmente, as desigualdades persistentes na divisão social do trabalho, trazendo assim, uma dominação masculina. Diante disso, o termo gênero estará totalmente ligado à sexualidade, porque para ser homem e ser mulher é necessário ter um corpo que estabilize a identidade de gênero, surgindo a "distinção entre as noções de diferença/semelhança e de igualdade/desigualdade" (COSTA, 2009, p.196).

Sem embargo, o processo de modernização da sociedade, através da inserção das mulheres no ensino superior e nas profissões qualificadas, causou um rompimento no pensamento de que elas pertenciam apenas ao privado e a ocupações inferiores. Isso representou uma tomada de consciência pelos direitos das mulheres, que por sua vez atingiu diversos países como Austrália, Finlândia, Noruega, Dinamarca, e afetou também o Brasil. Contudo, para compreender o processo de construção da cidadania brasileira, é necessário entender os arranjos na política do Brasil Republicano.

A Constituição de 1891 visava os interesses das oligarquias rurais, e proibia o direito de votar às mulheres, analfabetos, menores de 21 anos, entre outros. Embora tenham sido impedidas, as brasileiras foram em busca do direito de votar e serem votadas, levando-as a criar o Partido Republicano Feminino, considerado pioneiro na luta e na mobilização das mulheres pela conquista do voto (CEVA; SCHUMAHER, 2015, p.55). Enquanto, no cenário mundial, as mulheres neozelandesas foram as primeiras a conquistar o direito de voto em 1893.

As sufragistas brasileiras buscavam várias maneiras de romper o cerco que as impediam de serem cidadãs, que além do sufrágio, as precárias condições do trabalho feminino também estavam na pauta das feministas. Em 1927 uma nova Lei Eleitoral foi 
aprovada no estado do Rio Grande do Norte, dando abertura para que no dia 25 de novembro de 1927, a professora Celina Guimarães Viana se tornasse a primeira eleitora brasileira, a partir de um parecer favorável concedido pela justiça do Rio Grande do Norte. A conquista de Celina Guimarães contribuiu para a transformação do período da Primeira República num palco de várias lutas pelo voto feminino. Isso porque a edificação da cidadania no país se concretizou a partir do período republicano, quando a cidadania perde o caráter de privilégio que havia adquirido durante os períodos anteriores da história brasileira, e passa a ser um direito de todos. Apesar das diversas denúncias de fraudes nas eleições da época, é importante valorizar a existência dessas eleições como uma forma de exercer a cidadania, e a busca por direitos sociais. (GOMES, 2009, p. 162).

Os anos de 1930 foram marcados pela ascensão de Getúlio Vargas, durante o seu governo e através de muitos debates, o voto feminino e secreto foi introduzido no Código Eleitoral Provisório, através do Decreto no 21.076 de 24 de fevereiro de 1932, tornando-se, nesse âmbito, a maior conquista feminina do século XX, o direito de votar e serem votadas, ato que se consagrou como passo inicial para instaurar o princípio da igualdade entre os sexos. Mas as mudanças não pararam por aí, a nova e terceira Constituição brasileira de 1934 foi promulgada em uma ampla Assembleia Nacional Constituinte, nela ocorreu a primeira participação feminina (CEVA; SCHUMAHER, 2015, p.90). A nova Constituição estabeleceu também direitos à classe trabalhadora. Após 60 anos da maior conquista feminina, a década de 1990 ficou conhecida por ampliar os direitos políticos das mulheres com relação à representação política, porque se estabeleceu a primeira reserva de vagas para as mulheres nas listas de candidaturas em eleições proporcionais através da Lei no 9.100 de 1995, prevendo que cada partido apresentasse um mínimo de $20 \%$ de candidatas. Em 1997, a norma de reserva de vagas foi ampliada pela Lei $\mathrm{n}^{\circ}$ 9.504, que estendeu a medida para os demais cargos eleitos por voto proporcional, na Câmara dos Deputados, nas Assembleias Legislativas Estaduais e na Câmara Distrital, garantindo não mais uma cota mínima para as mulheres, mas uma cota mínima de $30 \%$ e uma cota máxima de $70 \%$ para qualquer um dos sexos, aplicando o princípio de igualdade entre homens e mulheres. (CEVA; SCHUMAHER, 2015, p. 216).

A Lei $n^{\circ} 9.504$ de 30 de setembro de 1997 que estabeleceu as normas para as eleições brasileiras sofreu novamente alterações em 2009. No intuito de buscar aprimorar e tornar as eleições mais equilibradas no ponto de vista da equidade. A lei é bastante extensa e trata de diversos assuntos que regem o processo eleitoral brasileiro, como a propaganda e registro de candidatos, doações para candidatos e outros. Todavia, o artigo da lei que rege a nossa pesquisa, corresponde ao número de vagas dos partidos políticos. Pois, compreende-se que as 
mudanças no quantitativo de vagas para os partidos políticos representaram o princípio de equidade política, porque os partidos políticos foram obrigados a introduzir as mulheres nesses espaços tradicionalmente ocupados por homens. Dessa forma, delineamos a pesquisa a partir da lei de cotas e as transformações que ela trouxe para o cenário político brasileiro.

Pois entendemos que as cotas de gênero no processo eleitoral representam uma ação afirmativa promovida pelo Estado. Tendo em vista que é necessário garantir uma plena participação das mulheres em todos os níveis de decisão na vida política, econômica e pública. Essa é uma medida de ação positiva destinada a promover a igualdade entre os sexos, ao reconhecer que as mulheres são fundamentais para a democracia. E um ato louvável que tem como principal escopo combater o retrógado machismo político eleitoral.

A análise sobre as trajetórias políticas tem sido foco de vários estudos, com intuito de compreender a dinâmica de grupos que detém o poder, e acompanhar como esses permanecem exercendo sua autonomia dentro de diversas sociedades. Como já se ressaltou, utilizamos a prosopografia para investigar e traçar o perfil político das mulheres eleitas em Roraima. Toda abordagem prosopográfica é composta por algumas etapas. Para a pesquisa escolhemos três: sendo a primeira o estabelecimento de uma lista geral de indivíduos que interessam para a pesquisa. A segunda consistiu em levantar a documentação desses indivíduos, remontando os momentos importantes de sua vida e carreira. Esta etapa é crucial, pois exigiu cuidado no tratamento dos dados. A última etapa consistiu em analisar a partir do material reunido, o conjunto de pontos em comum e as particularidades dos indivíduos.

Para traçar o perfil das mulheres eleitas em Roraima, escolhemos a ex-governadora Suely Campos do (PP); a prefeita da capital Boa Vista, Teresa Surita do (PMDB); a exsenadora Angela Maria Gomes Portela do (PDT); e, a deputada federal Shéridan Estérfany Oliveira de Anchieta do (PSDB). Após a escolha, construímos um quadro com as seguintes informações: nome, idade, cidade de origem, origem familiar, casamento, filhos, formação, cargo político, ingresso no partido político, partido atual e número de candidaturas, conforme o quadro 1: 
Quadro 1: Informações sobre o perfil das mulheres eleitas em Roraima.

\begin{tabular}{|c|c|c|c|c|}
\hline Nome & $\begin{array}{l}\text { Angela Maria } \\
\text { Gomes Portela }\end{array}$ & $\begin{array}{c}\text { Maria Teresa } \\
\text { Saenz Surita }\end{array}$ & $\begin{array}{c}\text { Shéridan Estérfany } \\
\text { Oliveira de } \\
\text { Anchieta }\end{array}$ & $\begin{array}{c}\text { Maria Suely Silva } \\
\text { Campos }\end{array}$ \\
\hline $\begin{array}{c}\text { Data de } \\
\text { Nascimento }\end{array}$ & 03/02/1962 & $14 / 08 / 56$ & $11 / 04 / 84$ & $14 / 05 / 53$ \\
\hline Cidade Natal & Coreaú (CE) & São Manuel (SP) & Boa Vista (RR) & Boa Vista (RR) \\
\hline $\begin{array}{c}\text { Origem } \\
\text { Familiar } \\
\text { (Pai Mãe) }\end{array}$ & $\begin{array}{c}\text { Francisco das } \\
\text { Chagas Gomes e } \\
\text { Maria Socorro } \\
\text { Araújo Gomes }\end{array}$ & $\begin{array}{l}\text { Antônio Saenz } \\
\text { Surita e Aurélia } \\
\text { Saenz Surita }\end{array}$ & $\begin{array}{c}\text { Maria Helena } \\
\text { Souza Oliveira e } \\
\text { José Santos } \\
\text { Oliveira }\end{array}$ & $\begin{array}{c}\text { Antônio Menezes } \\
\text { da Silva e Maria } \\
\text { América Sousa e } \\
\text { Silva }\end{array}$ \\
\hline Cônjuge & $\begin{array}{l}\text { Marido Francisco } \\
\text { Flamarion Portela } \\
\text { (PTC) governador } \\
\text { de Roraima (2000- } \\
\text { 2001) (2002-2004) }\end{array}$ & $\begin{array}{c}\text { Ex-marido, o } \\
\text { senador Romero } \\
\text { Jucá (PMDB), e } \\
\text { ex-governador de } \\
\text { Roraima (1988- } \\
\text { 1989) }\end{array}$ & $\begin{array}{l}\text { Ex-marido José de } \\
\text { Anchieta Júnior } \\
\text { (PSDB), } \\
\text { governador de } \\
\text { Roraima (2007- } \\
\text { 2009) (2010-2013). }\end{array}$ & $\begin{array}{c}\text { Marido Neudo } \\
\text { Campos (PP), } \\
\text { governador de } \\
\text { Roraima (1994- } \\
\text { 1997)(1998-2000). }\end{array}$ \\
\hline Filhos & $\begin{array}{l}\text { Ilana Portela e } \\
\text { Mariana Portela }\end{array}$ & $\begin{array}{l}\text { Ana Paula Surita e } \\
\text { Luciana Surita. }\end{array}$ & $\begin{array}{c}\text { Julia e Lara } \\
\text { Anchieta }\end{array}$ & $\begin{array}{l}\text { Emilia Santos, } \\
\text { Daniele Araújo, } \\
\text { Guilherme } \\
\text { Campos. }\end{array}$ \\
\hline Formação & $\begin{array}{c}\text { Letras - Faculdade } \\
\text { de Filosofia Dom } \\
\text { José de Sobral } \\
(\mathrm{CE})\end{array}$ & $\begin{array}{c}\text { Turismo - } \\
\text { Faculdade de } \\
\text { Turismo do } \\
\text { Morumbi (SP) }\end{array}$ & $\begin{array}{c}\text { Psicologia - } \\
\text { Faculdades } \\
\text { Cathedral (RR). }\end{array}$ & $\begin{array}{c}\text { Letras - } \\
\text { Universidade } \\
\text { Federal de Roraima } \\
\text { (RR) }\end{array}$ \\
\hline $\begin{array}{l}\text { Cargo } \\
\text { Político }\end{array}$ & Ex-Senadora & $\begin{array}{c}\text { Prefeita de Boa } \\
\text { Vista - (RR) }\end{array}$ & Deputada Federal & $\begin{array}{c}\text { Ex-Governadora de } \\
\text { Roraima }\end{array}$ \\
\hline Salário & $\mathrm{R} \$ 33.763,00$ & $\mathrm{R} \$ 18.000,00$ & $\mathrm{R} \$ 33.763,00$ & $\mathrm{R} \$ 30.900,00$ \\
\hline $\begin{array}{l}\text { Ingresso } \\
\text { Partido } \\
\text { Político } \\
\end{array}$ & $\begin{array}{l}\text { Filiou-se em } 2005 \\
\text { ao (PTC) }\end{array}$ & $\begin{array}{c}\text { Filiou-se em } 1990 \\
\text { ao (PDS). }\end{array}$ & $\begin{array}{c}\text { Filiou-se em } 2013 \\
\text { ao (PSDB) }\end{array}$ & $\begin{array}{l}\text { Filou-se em } 1990 \\
\text { ao (PDS). }\end{array}$ \\
\hline $\begin{array}{c}\text { Partido } \\
\text { Atual }\end{array}$ & (PDT) & (PMDB) & (PSDB) & (PP) \\
\hline
\end{tabular}

Fonte: Dicionário Histórico Biográfico Brasileiro.

A primeira característica em comum encontrada entre as candidatas foi que todas elas foram ou são esposas de ex-governadores do estado de Roraima. Começando por Maria Teresa Saenz Surita do (PMDB) atualmente prefeita de Boa Vista (RR), no passado era conhecida como Teresa Jucá. Nascida em São Manuel (SP), migrou para o estado junto com seu ex-marido Romero Jucá, que a convite do governo federal foi nomeado governador do Território de Roraima entre os anos de 1988 e 1989. Também temos a atual governadora do estado Suely Campos do (PP), nasceu em Boa Vista (RR), é casada com o ex-governador de Roraima, Neudo Campos também do PP.

A próxima é a nossa única ex-senadora mulher, Angela Gomes Portela (PDT), nasceu na cidade de Coreaú (CE), e mudou-se para Roraima em 1985, junto com seu marido 
Francisco Flamarion Portela, que exerceu o cargo de governador do estado em 2000 quando o titular Neudo Campos renunciou ao cargo. E, por fim, a deputada federal Shéridan Estérfany de Oliveira Anchieta (PSDB), que foi casada com o ex-governador José de Anchieta Junior (PSDB), que governou Roraima entre os anos de 2007 a 2013 (Dicionário Histórico Biográfico Brasileiro, 2013).

No que diz respeito ao primeiro contato dessas mulheres com a política, foi onde encontramos a nossa segunda característica em comum: duas delas iniciaram seus trabalhos como primeira-dama. Como é caso de Teresa Surita, ocupou o cargo de Coordenadora de Ação Social do governo do estado, trabalhando em projetos voltados à inclusão social, entre 1989 e 1990 e, com isso, conquistou prestígio e popularidade. Foi o pontapé para ingressar na carreira política, em 1990, ao ser eleita deputada federal pelo PDS. Dois anos depois, em 1992, almejando voos maiores, renunciou ao cargo para assumir a prefeitura da cidade de Boa Vista, repetindo a façanha nas eleições de 2000 e 2004 (CEVA; SCHUMAHER, 2015, p. 209). Após o divórcio optou por substituir o tradicional sobrenome do marido, Jucá. O que parecia arriscado deu certo, pois Teresa já havia construído uma imagem positiva na política, independente do seu companheiro. Nas eleições de 2012, foi a única mulher vitoriosa nas urnas como prefeita. Já nas eleições de 2016, reelegeu-se para o seu $5^{\circ}$ mandato no âmbito político.

A próxima primeira-dama foi Suely Campos, nomeada secretária do Estado do Trabalho e Bem-Estar Social, de 1997 a 2002, durante o governo do seu marido Neudo Campos. Nesta ocasião, foi presidente do conselho da Defesa de Direitos da Mulher, vinculado à secretaria. Em sua gestão, implantou o programa Centro Socioeducativo. O primeiro partido ao qual se filiou foi o PPB. Mas mudou de partido algumas vezes, elegeu-se deputada federal pelo DEM nas eleições de 2002. Na câmara dos deputados assumiu a agenda das mulheres, tornando-se titular da Comissão Feminização da Pobreza no Brasil. Foi também titular da Comissão Parlamentar Mista de Inquérito $\left(\mathrm{CPMI}^{6}\right)$ da Exploração Sexual de Crianças e Adolescentes (CEVA; SCHUMAHER, 2015, p. 327).

A ex-senadora Angela Portela antes de ter sido primeira-dama, assim que chegou ao estado, esteve a frente de movimentos sociais voltados para as causas das mulheres, dos idosos, dos deficientes, dos trabalhadores, rurais, entre outros. Em 2005, filiou-se ao (PTC), partido pelo qual concorreu e ingressou na Câmara Federal nas eleições de 2006 (CEVA; SCHUMAHER, 2015, p. 345). Esses dados expõem que o processo de entrada dessas

\footnotetext{
${ }^{6}$ A Comissão Parlamentar Mista de Inquéritos é formada por representantes do Senado Federal e Câmara dos Deputados com o objetivo de investigar supostas irregularidades no setor público.
} 
mulheres para o cenário político roraimense ocorreu através dos vínculos de parentescos. $\mathrm{O}$ cargo de primeira-dama foi o primeiro e principal meio para que essas mulheres iniciassem seu projeto de carreira política. Mostrando que o percurso político trilhado por essas mulheres é bem diferente das sufragistas, tendo em vista que não houve um processo de luta de gênero para adentrar esses espaços, uma vez que os arranjos familiares se tornaram a forma mais fácil de introduzir-se na elite política.

Constatamos também, que novos atores políticos passaram a se aliar a grupos fortes do estado, como é o caso de José Anchieta e Shéridan Anchieta, que se uniram a Ottomar Pinto durante o seu governo. Antes de se tornar primeira dama, Shéridan Anchieta exerceu o primeiro cargo com apenas 21 anos, ao ser nomeada assessora chefe de comunicação da Câmara Municipal de Boa Vista em 2005. No ano seguinte, atuou na Coordenadoria de Comunicação do Governo do Estado de Roraima. Em 2007 seu marido, então vicegovernador, assumiu o cargo de governador de Roraima após a morte de Ottomar Pinto, e Shéridan se tornou primeira-dama do estado de Roraima. Durante o mandato de seu marido como governador de Roraima, Shéridan foi secretária de Estado da Promoção Humana e Desenvolvimento (Dicionário Histórico Biográfico Brasileiro, 2013).

Outro aspecto importante entre as candidatas é que todas possuem título universitário, como vimos na primeira seção, ter uma formação superior sempre foi um dos principais requisitos para adentrar na carreira política. Através do perfil social das mulheres percebemos o poder de sustentação das famílias em Roraima. O exemplo de Teresa Surita, que com apoio de Romero Jucá elegeu-se mais duas vezes para o cargo da prefeitura de Boa Vista, nas eleições de 2012, sendo a única mulher vitoriosa nas urnas como prefeita, e sendo reeleita em 2016. Esse dado revela que Teresa Surita permaneceu efetivamente ligada ao seu ex-marido, assim como as outras mulheres pesquisadas.

As estruturas de parentesco é um aspecto enraizado na sociedade roraimense, como o caso da ex-governadora de Roraima Suely Campos (PP), quando nas eleições de 2014 substituiu às pressas o marido na disputa, Neudo Campos, que teve a candidatura barrada pela Justiça. Considerado ficha suja ${ }^{7}$, Neudo Campos foi citado como envolvido nos escândalos conhecidos como dos Gafanhotos, das Bolachas e da Merenda. Nesse sentido, é possível perceber que mesmo ocupando diversos cargos, Suely Campos não se movimenta de maneira autônoma, pois está sempre a sombra do seu marido, até mesmo na hora de substituí-lo. O

\footnotetext{
${ }^{7}$ A Lei Complementar no 135, também conhecida como Lei da Ficha Limpa, estabelece casos de inelegibilidade, prazos de cessação e determina outras providências, para incluir hipóteses de inelegibilidade que visam proteger a probidade administrativa e moralidade no exercício do mandato (PLANALTO, 2010).
} 
nepotismo é outra característica que observamos na família Campos, quando Suely nomeou 19 parentes para secretarias do Estado, dentre eles suas próprias filhas Danielle Araújo e Emília Santos para a Casa Civil e para Secretaria Estadual de Trabalho e Bem-Estar Social (SETRABES), sua irmã Selma Mulinari para a Secretaria Estadual de Educação, e para o cargo de secretário adjunto da Secretaria de Estado da Agricultura, Pecuária e Abastecimento (SEAPA), o irmão João Paulo de Souza e Silva, mostrando que há presença de seus familiares em várias instâncias administrativas. O número de posições ocupadas revela uma liderança da família Campos na sociedade roraimense (Folha de Boa Vista, 2015).

A pesquisa também nos mostra que ainda há uma forte disputa entre os grupos liderados por alianças nacionais, como é o caso de Romero Jucá e Teresa Surita versus alianças locais, representada pela família Campos. E mesmo com o surgimento de ações transformadoras, e entrada dessas mulheres para cargos políticos, elas não rompem com grupo político de origem. Ao combinarmos as informações obtidas descobrimos que essas mulheres são extensões de poder exercidas por maridos e ex-maridos. Diante do fato que, esses vínculos familiares são essenciais para que ambos se mantenham no poder.

Ao estudarmos a trajetória de vida das quatro candidatas eleitas em Roraima, compreendemos a importância da entrada delas para os partidos políticos, suas candidaturas e projetos políticos, de modo que, essas ações abrem as portas para que todas as mulheres brasileiras tenham mais visibilidade nas questões políticas. Elas representam um momento importante da história do estado de Roraima, diante do fato que muitos anos se passaram até que uma mulher chegasse a um cargo político em Roraima. Embora, a trajetória política dessas quatros mulheres tenha sido marcada pela predominância de conchavos políticos e arranjos familiares. Mesmo assim, romperam com incontáveis barreiras para a conquista de uma maior participação nas esferas de poder.

\section{Considerações finais}

Traçar o perfil das mulheres eleitas em Roraima por meio de suas configurações familiares e redes de parentesco nos permitiu repensar as condições da relação entre as esferas familiares e políticas. Concluímos, através do mapeamento do perfil das mulheres que a família Campos e a Jucá/Surita possuem significativa presença no cenário político roraimense. Ao continuarem introduzindo membros da sua família em cargos públicos, com o intuito de estender seu poder político, tendo em vista que os familiares continuam acumulando cargos políticos ao longo do tempo. 
A prosopografia, metodologia que permitiu registrar todas as informações coletadas em um espectro de fontes diversificado, como o Dicionário Histórico Biográfico Brasileiro, as autoras Antonia Ceva e Maria Schumaher, e o jornal Folha de Boa Vista. Embora haja muitas informações sobre cada integrante do grupo, a meta sempre foi construir um quadro que apontasse uma tendência na composição desse grupo. Mergulhamos no universo biográfico de cada mulher, e com isso foi possível constatar a estratégia de ascensão social apoiada na dinâmica das redes sociais, e verificar se havia uma continuidade de certos grupos políticos em Roraima. Desse modo, compreendemos que a presença direta das relações de parentesco tornou um instrumento eficaz para a manutenção do poder político. Através das redes de proteção, políticos conseguem se manter no poder em Roraima. As chamadas famílias tradicionais continuam exercendo poder independente das transformações sociais, econômicas e políticas do estado.

Percebemos também que o advento da Lei $\mathrm{n}^{\circ}$ 12.034/2009, que teve como objetivo implantar a igualdade entre homens e mulheres nos partidos políticos, é apenas uma das primeiras medidas, que o caminho para a igualdade nos partidos políticos ainda é extenso. Diante do fato de que, mesmo depois de duas eleições notamos que houve pouca evolução no sentindo de obter um resultado mais efetivo no tratamento da igualdade em relação aos direitos políticos. Além disso, há indícios de que os partidos políticos burlam a lei, preenchendo apenas o quantitativo necessário exigido, cujo foco sempre será eleger homens. Percebemos assim, que no geral, essa entrada das mulheres nos espaços políticos ocorre de forma lenta. $\mathrm{E}$ as mulheres da pesquisa, conseguem adentrar os ambientes de poder de forma mais fácil, através dos mandatos políticos de seus maridos. E somente depois de terem contato com os cargos públicos, é que se reconhecem capazes de trilhar uma carreira política, no entanto, continuam mantendo a dependência em relação aos maridos, pois como foi discutido ao longo do trabalho, as alianças familiares representam uma boa estratégia para se manter no poder.

Árduo foi o caminho percorrido pelas mulheres ao longo da história da República brasileira para ver reconhecida sua condição de cidadã e titular de direitos políticos. Conquistaram o direito de ter voz na sociedade, no entanto, notamos que as mulheres cujos perfis foram traçados nesta pesquisa, continuam sendo apenas uma transferência do poder. Mulheres que são um modelo bem diferente daquele que vimos com relação às sufragistas que lutavam pelo direito ao voto. Fazem parte de uma elite política e se beneficiam de influências e caminhos já trilhados por seus grupos. A lei de cotas é ainda o primeiro passo para vencer o pensamento dominante enraizado na sociedade brasileira. 
Sendo assim, entendemos que a luta por igualdade no espaço público será um processo bem mais difícil, a exigência e proporcionalidade entre candidatos do sexo masculino e do sexo feminino como condição de elegibilidade por si só não consegue acabar com todo um histórico de machismo que ocorre em todas as esferas do nosso país. Verifica-se que a desigualdade de gênero, é uma questão histórica. Somente uma ação política que leve realmente em conta todos os efeitos da dominação, esta que se exerce em todos os momentos da vida feminina. Trabalhar contra as contradições, continua sendo o caminho para contribuir para o desparecimento progressivo dessas desigualdades.

\section{Fontes}

DICIONÁRIO Histórico Biográfico Brasileiro. Disponível em: http://www.fgv.br/cpdoc/acervo/dicionarios/verbete-biografico/portela-angela. Acesso em: 18 junho 2018.

DICIONÁRIO Histórico Biográfico Brasileiro. Disponível em: http://www.fgv.br/cpdoc/acervo/dicionarios/verbete-biografico/portela-francisco-flamarion.

Acesso em: 18 junho 2018.

DICIONÁRIO Histórico Biográfico Brasileiro. Disponível em: http://www.fgv.br/cpdoc/acervo/dicionarios/verbete-biografico/anchieta-junior-jose-de.

Acesso em: 18 junho 2018.

DICIONÁRIO Histórico Biográfico Brasileiro. Disponível em: http://www.fgv.br/cpdoc/acervo/dicionarios/verbete-biografico/neudo-ribeiro-campos. Acesso em: 18 junho 2018.

DICIONÁRIO Histórico Biográfico Brasileiro. Disponível em: http://www.fgv.br/cpdoc/acervo/dicionarios/verbete-biografico/romero-juca-filho. Acesso em: 18 junho 2018.

DICIONÁRIO Histórico Biográfico Brasileiro. Disponível em: http://www.fgv.br/cpdoc/acervo/dicionarios/verbete-biografico/maria-sueli-silva-campos. Acesso em: 18 junho 2018.

DICIONÁRIO Histórico Biográfico Brasileiro. Disponível em: http://www.fgv.br/cpdoc/acervo/dicionarios/verbete-biografico/teresa-saenz-surita-juca.

Acesso em: 18 junho 2018.

DICIONÁRIO Histórico Biográfico Brasileiro. Disponível em: http://www.fgv.br/cpdoc/acervo/dicionarios/verbete-biografico/otomar-de-sousa-pinto Acesso em 18 junho 2018.

FOLHA, W. Governadora recebe $\mathrm{R} \$ 30$ mil e prefeita tem salário de R \$ 18 mil. Disponível em: http://folhabv.com.br/noticia/Governadora-recebe-R--30-mil-e--prefeita-tem-salario-deR--18-mil/7569. Acesso em: 26 junho 2018.

MERELES, C. Quanto ganha um senador? Disponível em: <http://www.politize.com.br/quanto-ganha-senador/>. Acesso em: 26 junho 2018

RESENDE, L. Salário de deputado x salário de professor: compartilhe informações corretas. Disponível em: https://piaui.folha.uol.com.br/lupa/2018/02/05/salario-deputado-professor/. Acesso em: 26 de junho 2018.

TRIBUNAL Superior Eleitoral. Disponível em: <http://www.tse.jus.br/>. Acesso em: 19 janeiro 2018. 
TRIBUNAL Regional Eleitoral de Roraima. Disponível em: http://www.tse.jus.br/eleicoes/eleicoes-anteriores/eleicoes-2002. Acesso em: 19 janeiro 2018. Wikipédia. Disponível em: https://pt.wikipedia.org/wiki/Sh\%C3\%A9ridan_Oliveira. Acesso em: 18 junho 2018.

\section{Legislação Consultada}

BRASIL. Lei $\mathrm{n}^{\circ}$ 9.504, de 30 de setembro de 1997. Estabelece normas para as eleições. Brasília. (disponível em: http://www.planalto.gov.br/ccivil_03/leis/L9504.htm, acesso em: 19/01/2018)

BRASIL. Lei $n^{\circ}$ 9.034, de 29 de setembro de 2009. Altera as Leis nos 9.096, de 19 de setembro de 1995 - Lei dos Partidos Políticos, 9.504, de 30 de setembro de 1997, que estabelece normas para as eleições, e 4.737, de 15 de julho de 1965 - Código Eleitoral. Brasília. (disponível: http://www.planalto.gov.br/ccivil_03/_ato20072010/2009/lei/112034.htm, acesso em: 19/01/2018)

BRASIL, Lei Complementar $n^{\circ} 134$, de 05 de junho de 2010. Altera a Lei Complementar $n^{\circ}$ 64 de 18 de maio de 1990, que estabelece, de acordo com o $§$ 9o do art. 14 da Constituição Federal, casos de inelegibilidade, prazos de cessação e determina outras providências, para incluir hipóteses de inelegibilidade que visam a proteger a probidade administrativa e a moralidade no exercício do mandato. Brasília. (disponível: http://www.planalto.gov.br/ccivil_03/leis/lcp/Lcp135.htm, acesso em: 26/06/3018)

\section{Referências Bibliográficas}

ALBERNAZ, Cássio A. Da história política dos "grandes homens" a prosopografia das elites políticas: Considerações historiográficas e metodológicas. In: Anais do XXVI Simpósio Nacional de História - ANPUH. São Paulo, julho. 2011.

BARICKMAN, Bert J. LOVE, Joseph L. Elites regionais. In: HEINZ, Flávio M. Orgs. Por outras histórias das elites. Rio de Janeiro: Editora FGV, 2006.

CEVA, Antonia; SCHUMAHER, Maria Aparecida. Mulheres no Poder: Trajetórias na Política a partir da Luta das Sufragistas no Brasil. Rio de Janeiro: Edições de Janeiro, 2015.

CODATO, Adriano. Metodologias para a identificação de elites: três exemplos clássicos. In: CODATO, Adriano. PERISSINOTTO Renato. (Orgs). Como estudar elites. Curitiba: Ed. UFPR, 2015.

CORINIFF, Michel L. A elite nacional. In: HEINZ, Flávio M. (Org). Por outras histórias das elites. Rio de Janeiro: Editora FGV, 2006.

COSTA, Suely. Gênero e História. In: ABREU, Martha. SOIHET, Rachel (Orgs). Ensino de história: conceitos, temáticas e metodologia. Rio de Janeiro: Casa da Palavra, 2009.

FERREIRA, Marieta. História, tempo presente e história oral. Topoi, v.3, n.5, p. 314-332 2002.

FERREIRA, Marieta. História do tempo presente: desafios. In: Cultura Vozes, Petrópolis, v. 94, nº 3, p.111-124, 2000.

GOMES, Angela de Castro. Venturas e Desventuras de uma república de Cidadãos. In: ABREU, Martha; SOIHET, Rachel (Org.). Ensino de história: conceitos, temáticas e metodologia. Rio de Janeiro: Casa da Palavra, 2009.

LALOUETTE, Jacqueline. Do exemplo à série: história da prosopografia. In: HEINZ, Flávio M. Orgs. Por outras histórias das elites. Rio de Janeiro: Editora FGV, 2006. 
OLIVEIRA, Reginaldo Gomes de. A herança dos descaminhos na formação do Estado de Roraima. 2003. 378p. Tese (Doutorado em história) Faculdade de Filosofia, Letras e Ciências Humanas. USP, São Paulo 2003.

ROUSSO, Henry. Sobre a História do Tempo Presente. Tempo e Argumento, Florianópolis, v. $1, n^{\circ} .1$, p. $201-216$, jan/jun. 2009.

SANTOS, Raimundo Nonato G. dos. Entre cultura política, memória e política de identidade: sujeitos históricos em ação-Boa Vista- Roraima (1970- 1980). 2015. 342p. Tese (Doutorado em História Social) Pontifícia Universidade Católica de São Paulo, São Paulo, 2015.

SCOTT, Joan. Gênero: uma categoria útil para a análise histórica. Trad.: Christine Rufino Dabat e Maria Betânia Ávila. 1989.

STONE, Lawrence. Prosopografia. Revista Social Política, Curitiba, v.19, n.39, p.115-137, jun. 2011.

SWAIN, Tânia. Que história é essa? Revista Caminhos de História, v.14, n 2, jul/dez, 2009. 